\title{
Climate applicability study of building envelopes containing phase change materials
}

$\mathrm{Ru} \mathrm{Ji}^{1}$, Yaxian Zheng ${ }^{1}$, Zehui Zou ${ }^{1}$, Shen $\mathrm{Wei}^{2}$, and Shilin $\mathrm{Qu}^{1 *}$

1 School of Civil and Resource Engineering, University of Science and Technology Beijing, 100083, Beijing, P.R. China

2 Bartlett School of Construction and Project Management, University College London (UCL), WC1E 7HB, London, UK

*Corresponding author: q.shilin@163.com

\begin{abstract}
Building envelopes incorporating phase change materials (PCMs) can contribute to reducing the energy consumption of buildings and enhance indoor thermal environment comfort. In this study, two building models were developed in EnergyPlus to explore the applicability of using PCMs in different climate zones. Six significantly different cities from five climate zones in China have been investigated. The simulation results reflected that for climates with small fluctuation weather conditions, PCMs with appreciate transition temperature $T_{R}$ can contribute to positive influences on energy saving. For example, in Guangzhou, PCMs with $T_{R}$ of near $26^{\circ} \mathrm{C}$ and $22^{\circ} \mathrm{C}$ contribute to the highest energy saving rates of $12.0 \%$ and $12.4 \%$, for external and internal PCMs addition. And the ideal transition temperature for each climates is subjected to its own outdoor comprehensive temperatures and its indoor set temperature, for external and internal PCMs addition, respectively. For other climates with the big fluctuation weather condition, PCMs' latent heat function to the energy savings is not significant.
\end{abstract}


Keywords: Phase change material; applicability study; building envelopes; different climates.

\section{Introduction}

In recent decades, the energy demand of our society is continuously increasing, especially from the building sector [1]. As a major energy consuming sector (about $40 \%$ of world total primary energy [2], buildings are always required to provide comfortable indoor environment for the occupants, and this has led to great challenges to the application of energy [3]. Therefore, energy saving of building and improving the efficiency of their energy systems become necessary for sustainable development. For example, nearly net-zero energy buildings are a popular concept for future building development, and this can be achieved by different energy saving methods [4], such as passive design methods, system efficiency improvement and renewable energy usage. Among these methods, passive design is considered as an effective one [5].

In real applications, renovation design of building envelop plays an important role in passive design. Existing literatures have given two main types of energy efficient wall systems, namely, high-thermal insulation system [6-9] and thermal storage system, e.g. using phase change materials (PCMs) [10-15].

The use of thermal energy storage for building envelops has received great attention in recent years [16]. Numerous studies have explored the use of PCMs in building envelopes to enhance the indoor thermal environment and energy performance of buildings. In this research area, firstly, some researchers focused on the development of PCM-based technologies [17-22]. For example, Wang et al. [17] developed a new 
method for preparing PCMs, through investigating the effect of various methods on both the structures and thermal. Sarı [19] and Mankel [20] prepared a form-stable PCMs/cement composite after using characteristic techniques. Secondly, some other researchers studied the incorporation methods of PCMs into building envelopes [2326]. For instance, Boussaba et al. [23] prepared a composite bio-based PCM with lowcost and eco-friendly for use in building envelopes. Thirdly, some were also researchers doing experimental research on potential factors of energy saving effect of PCMs [2628]. For example, Berardi [28] found that PCMs with different transition temperatures is effective in climates with large yearly temperature fluctuations. Fourthly, there were some researchers analysing the energy storage mechanism of PCMs [29-31]. For example, Zhou et al. [31] study the heat-transfer mechanism of wallboards containing PCMs, and proposed that it would be affected by the melting temperature, thickness and so on. Finally, the heat discharge of PCMs is also an important part for its comprehensive utilization in buildings. For example, the thermal storage can be discharged with natural night ventilation, daily temperature fluctuation, or active systems [32-33].

Actually, there are numerous studies have explored the use of PCMs in building envelopes to enhance the indoor thermal environment and energy performance. However, there are few studies systematically exploring climate applicability of PCMs in building envelopes, especially in China. So it is needed to investigate the PCMs' heat mechanism firstly, then indicate the selection reference of PCMs, finally give the optimum phase transition temperature range for some adaptive climates. 
This study, therefore, was conducted and two building models (a simple cabin model and a more complicated model) were developed to discuss the PCMs' latent heat mechanism and give optimum transition temperature ranges for different climatic conditions, respectively.

\section{Methodology}

In this study, EnergyPlus with the CondFD algorithm has been used to predict the building's energy performance, due to its existing rigorous validation and verification studies for PCMs [34-37]. Here, the time discretization for calculation is $3 \mathrm{~min}$.

\subsection{Model descriptions}

Two simulation models, including a simple cabin model (Model-S) and a more complicated building model (Model-C), were developed as shown in Figure 1a and 1b, respectively. The Model-S was developed here to reveal the basic heat storage mechanism of PCMs when incorporated into building. The Model-C was developed according to a real building located in Beijing, as shown in Figure 1c, to justify the implementation of the main findings obtained from the simple model, and gave optimum transition temperature ranges for each climate.

In this study, the simple cabin model has dimensions of $2.6 \mathrm{~m} \times 2.6 \mathrm{~m} \times 2.6 \mathrm{~m}$, with one south-facing window $(1.5 \mathrm{~m} \times 1.5 \mathrm{~m})$. Secondly, to do applicability research of PCMs in the building envelope in different climates, a more complicated building model with $3956 \mathrm{~m}^{2}$ was further applied, and its interior load and HAVC system schedule will be considered. 


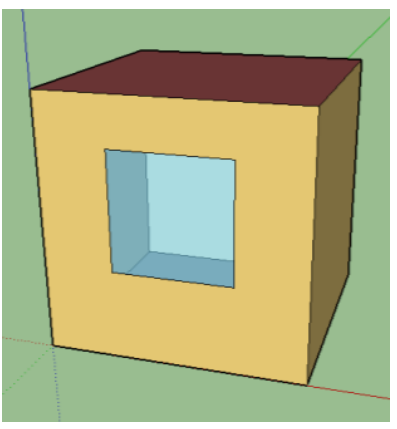

(a) A simple cabin model

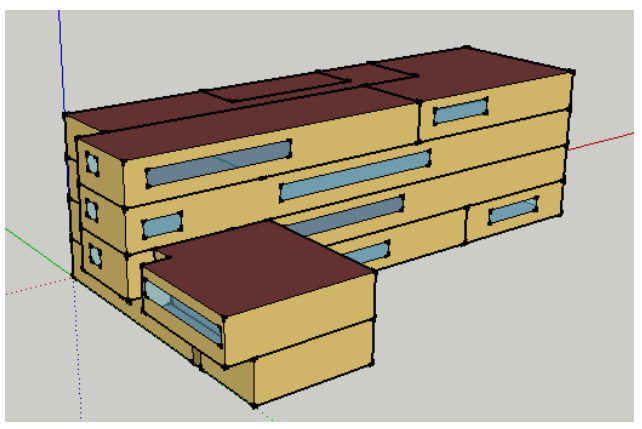

(b) A more complicated building model

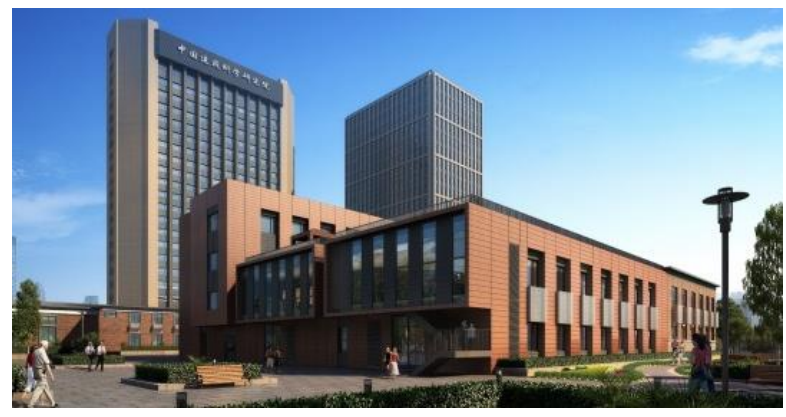

(c) A real building

Figure1: Simulation models used in this study

Table 1: Basic thermo-physical properties of construction materials

Table 1 has listed some basic thermo-physical properties for the construction materials used in this study. For Model-S, three different material compositions were used, namely, 1) a benchmark model (Model-S-1) with 150mm concrete floor, walls and roof; 2) a model (Model-S-2) with a 10mm PCM layer added to Model S-1; and 3) 
a model (Model-S-3) without PCMs but with the same U-values as Model S-2. In Model-S-2, the PCM layer was attached to the inner and outer surface of the building envelope separately to give indications on its impact.

Here, in order to investigate the ideal parameters of PCMs, the applied PCMs is a hypothetical material. In addition, to investigate PCMs' latent heat storage function on building energy use, "Solid PCMs" was carried out to keep Model-S-3 have the same U-values as Model-S-2. As shown in Table.1, basic thermo-physical properties in both "Solid PCMs" and PCMs were the same, while "Solid PCM" had no latent heat of fusion.

For Model-C, two kinds of construction compositions were applied. For ModelC-1, all exterior envelops were made of base constructions, including three layers: a $100 \mathrm{~mm}$ brick, a $200 \mathrm{~mm}$ reinforced concrete and a $19 \mathrm{~mm}$ gypsum board from outside to inside. For Model-C-2, a 50mm PCM layer was placed on the exterior surfaces of all vertical walls and roof.

\subsection{Indoor and outdoor meteorological parameters}

For the simulation in Model-S, Guangzhou, as a represented city in summer hot \& winter warm zone, was used as a weather file. For Model-C, six weather files for Guangzhou, Kunming, Shanghai, Lhasa, Beijing, and Harbin were applied as the input files, which represented respectively different kinds of weather zones, including summer hot \& winter warm zone with cooling supply needs, warm zone, summer hot $\&$ winter warm cold with cooling supply needs, cold zone with and without high solar radiation, frozen zone with heating supply needs. Here, all wall and roof surfaces were 
set to expose to the outdoor environment.

Figure 2 indicated that annual mean outdoor temperature and solar radiation intensity are $22.3{ }^{\circ} \mathrm{C}, 15.3{ }^{\circ} \mathrm{C}, 16.7{ }^{\circ} \mathrm{C}, 8.3{ }^{\circ} \mathrm{C}, 12.6^{\circ} \mathrm{C}, 4.1{ }^{\circ} \mathrm{C}, 67.4 \mathrm{~W} / \mathrm{m}^{2}$, and 133.5 $\mathrm{W} / \mathrm{m}^{2}, 107.0 \mathrm{~W} / \mathrm{m}^{2}, 232.4 \mathrm{~W} / \mathrm{m}^{2}, 151.2 \mathrm{~W} / \mathrm{m}^{2}, 148.0 \mathrm{~W} / \mathrm{m}^{2}$ for Guangzhou, Kunming, Shanghai, Lhasa, Beijing, and Harbin, respectively. Figure 2 also indicated that for both Guangzhou and Kunming, the fluctuations of mean outdoor temperature are weak, which will be good for the application of the PCMs due to the limit of PCMs' transition temperature $\left(T_{R}\right)$. In addition, it can also be found that, for Lhasa, the solar radiation intension in winter is high, leading to small fluctuation in its outdoor comprehensive air temperature, which will also result in a good function to its application of the PCMs.
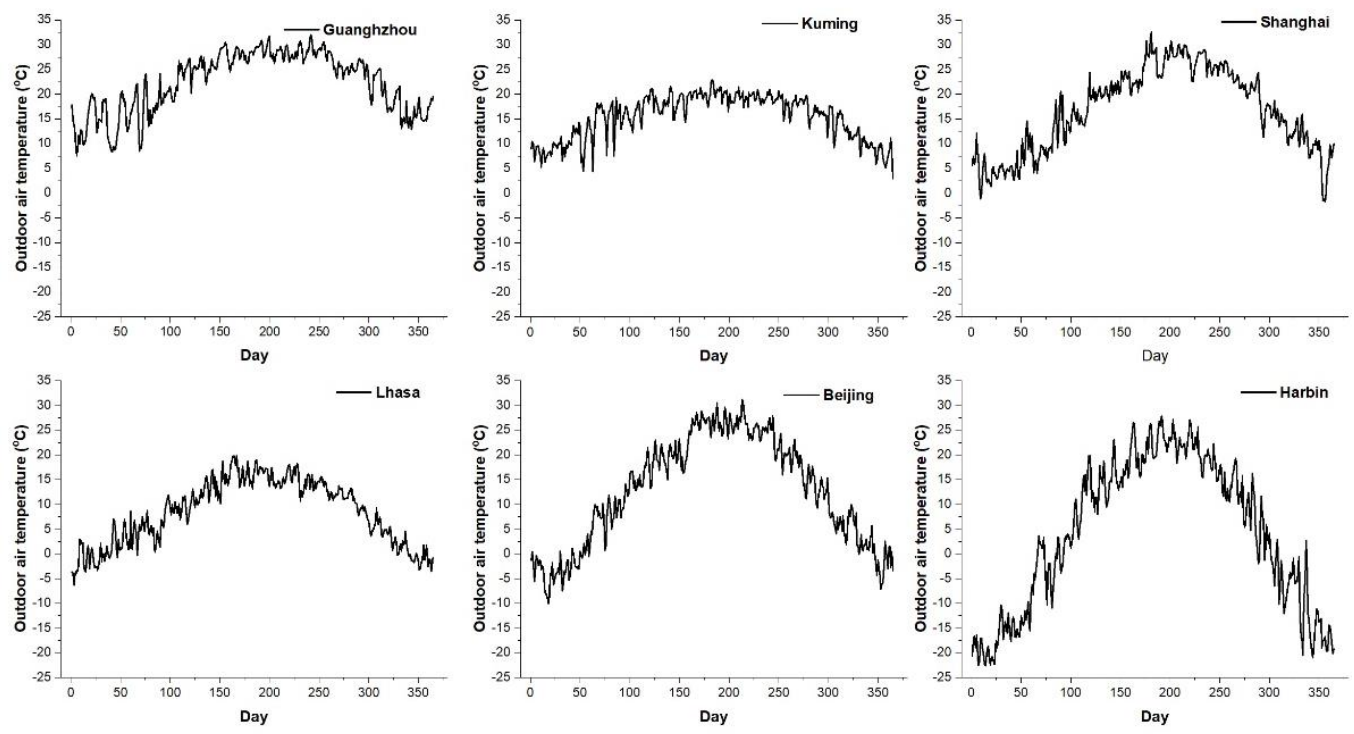

(a) Outdoor air temperature 

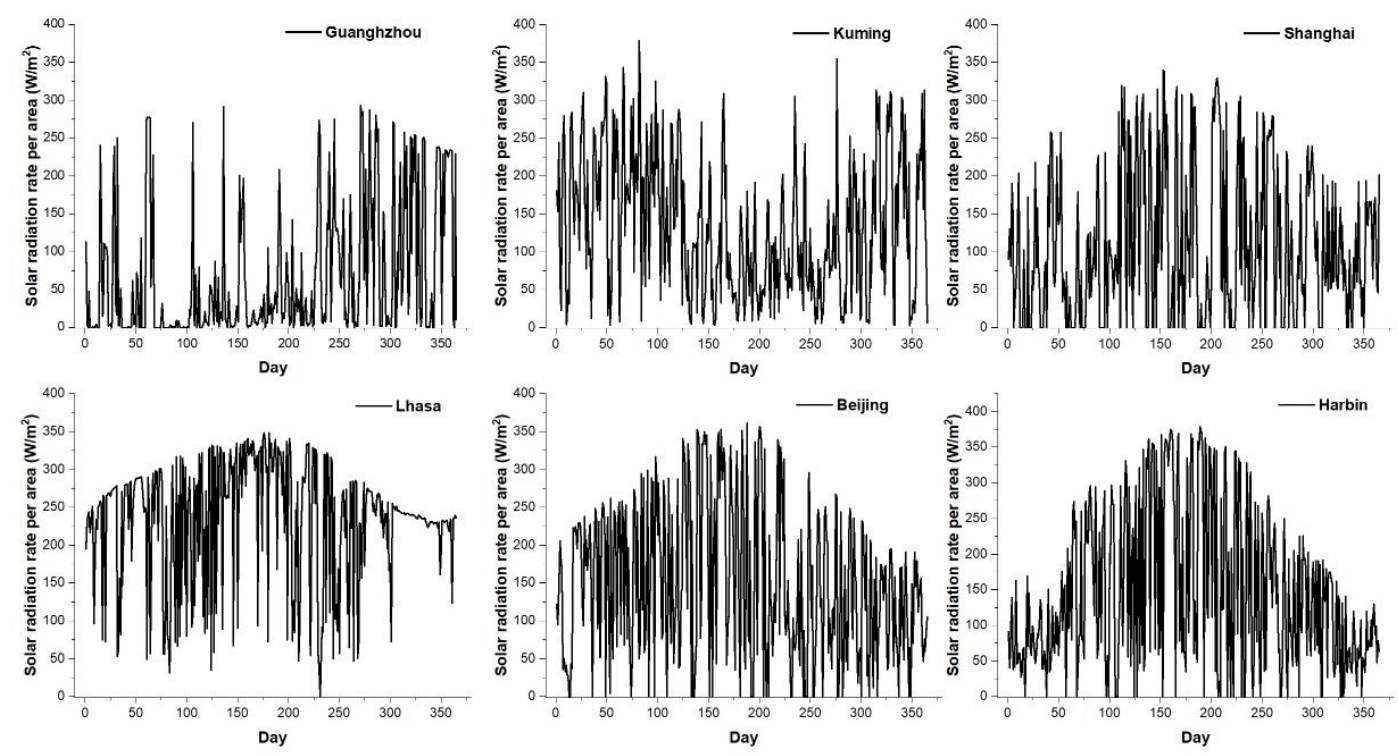

(b) Solar radiation rate per area

Figure 2: Annual outdoor meteorological parameters of six weather zones

To run both simulation models, the ideal load HVAC system was applied, which could keep the indoor air temperature at between $18^{\circ} \mathrm{C}$ and $26^{\circ} \mathrm{C}$. In addition, for Model-C, to give a more accurate predictive analysis of PCMs applicability, interior heat source, such as people, lights, electric equipment, was considered. Figure 3 gave the schedule of interior heat source and energy supply system.

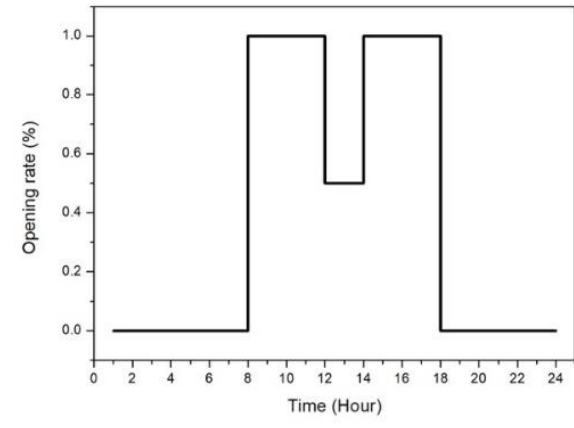

(a) Interior heat source

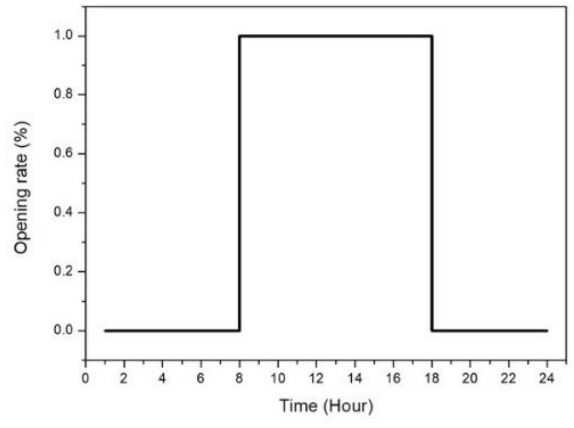

(b) Energy supply system

Figure 3: Schedules of interior heat source and energy supply system 


\subsection{Evaluation indexes}

For Model-S, to reveal heat storage mechanism of PCMs, daily and hourly heating or cooling loads ( $L_{D \text {-heat }}, L_{D-\text { cool }}, L_{H-h e a t}$, and $\left.L_{H-c o o l}\right)$ on special days and envelope surface temperatures ( $T_{\text {in }}$ and $\left.T_{\text {out }}\right)$ were applied as evaluation indexes. For Model-C, annual mean heating and cooling load $\left(L_{A}\right)$ was used as an index. In addition, in the Model-C, energy saving rate $(\eta / \%)$ was applied to evaluate the energy saving performance of PCMs, which was calculated by Equation (1), where $L_{A-1}$ and $L_{A-2}$ are annual heating and cooling load per square meter caused by the Model-C-1 and Model-C-2 without and with PCMs, respectively.

$$
\eta=\frac{L_{A-2}-L_{A-1}}{L_{A-1}}
$$

\section{Results and discussion}

\subsection{Heat transfer mechanism of PCMs}

In this section, the simulation studies were conducted in Model-S in Guangzhou and PCMs was separately integrated on the exterior and interior surfaces of building envelopes. Then daily and hourly heating or cooling loads $\left(L_{D-h e a t}, L_{D-c o o l}, L_{H-h e a t}\right.$, and $\left.L_{H-c o o l}\right)$ on special days and the corresponding envelop surface temperatures were analyzed. 


\subsubsection{Daily Load study}

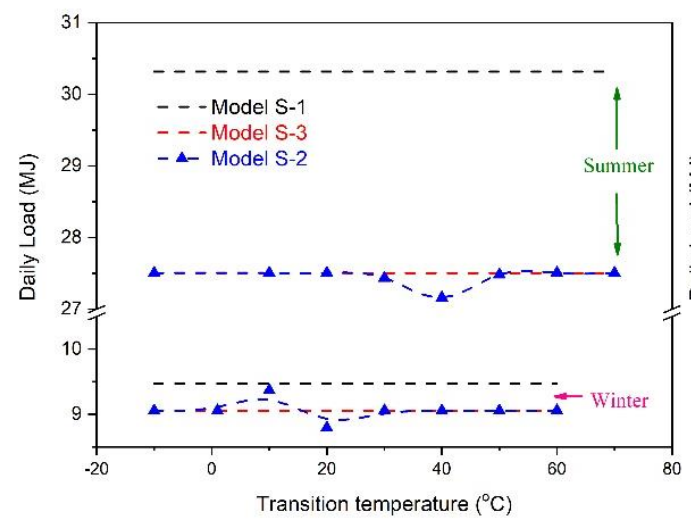

(a) PCMs added on exterior envelop

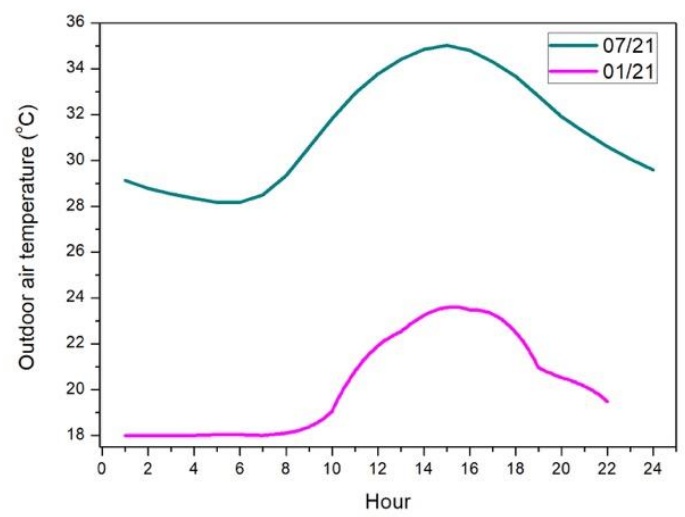

(c) Outdoor air temperature

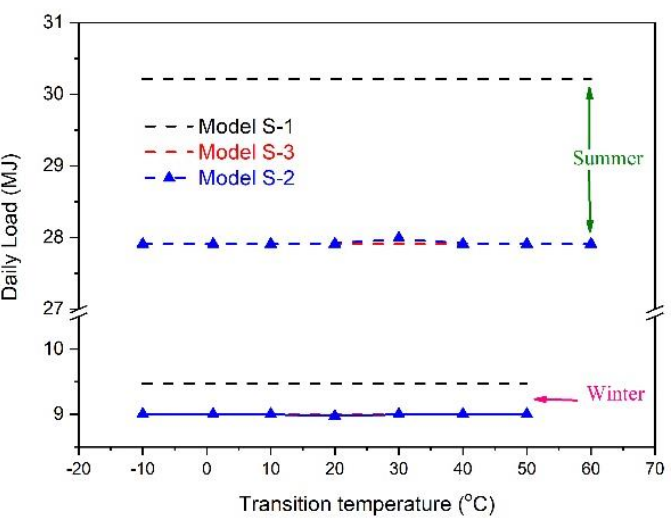

(b) PCMs added on internal envelop

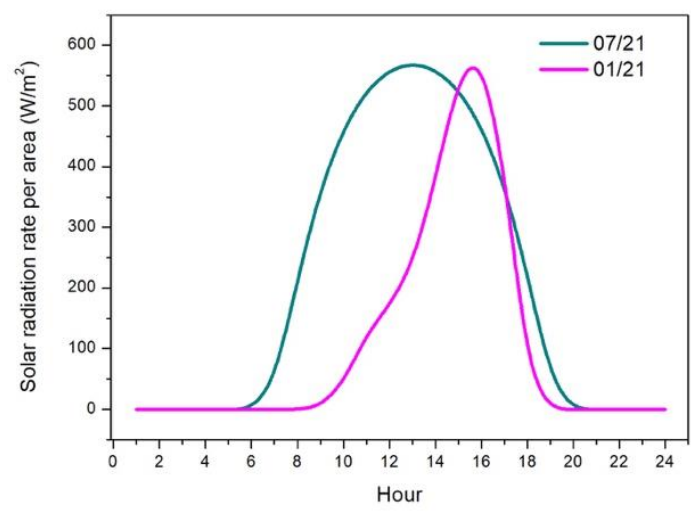

(d) Solar radiation rate per area

Figure 4: Daily loads and outdoor specially day weather condition for a simplified cabin model located in Guangzhou

Figure 4 indicates the daily loads for Model-S located in Guangzhou and the weather condition in special day. It shows that there are three lines in each picture, which represents loads from three models (Black dotted line for Model-S-1, the normal building with only concrete envelope; Blue dotted line for Model-S-2, the building with PCMs addition envelope; Red dotted line for Model-S-3, the building with the same Uvalues as Model-S-2).

Firstly, Figure 4 shows that there are of four groups' daily loads $\left(L_{D}\right)$, according to PCMs application position (external and internal of building envelope) and weather 
condition (summer and winter day). For all of four groups, the $L_{D}$ of Model-S-3 (Red dotted line) is always low than that of Model-S-1 (Black dotted line), which is due to an increase of thermal resistance of building envelopes incorporated by the "Solid PCMs" (i.e., the function of sensible heat of PCMs).

Secondly, compared with Model-S-3, $L_{D}$ of Model-S-2 (Blue dotted line) shows different trends in these four groups, and that is to say, latent heat of PCMs play a different role in building energy saving, subjects to its application position and weather condition. Specifically, Figure 4a shows $L_{D}$ curves for models with PCMs added on exterior envelope. In summer, comparing to $L_{D}$ in Model-S-3 (Red dotted line), $L_{D}$ in Model-S-2 (Blue dotted line) is further reduced in an appropriate range of PCMs' transition temperature $\left(T_{R}\right)$ of $30 \sim 50^{\circ} \mathrm{C}$. In winter, there are two trends. For high $T_{R}$ range of about $15 \sim 30^{\circ} \mathrm{C}, \mathrm{L}_{\mathrm{D}}$ is also reduced; while for low $T_{R}$ range of about $10 \sim 15^{\circ} \mathrm{C}$, $L_{D}$ increases instead. Then Figure $4 \mathrm{~b}$ shows $L_{D}$ curves for models with PCMs added on internal envelope. Different from the trends in Figure $4 a$, Figure $4 b$ indicates that in summer $L_{D}$ in Model-S-2 is slightly raised in a range of $T_{R}$ of near $30^{\circ} \mathrm{C}$, while in winter for a $T_{R}$ range of near $20^{\circ} \mathrm{C}, L_{D}$ decreases a little.

\subsubsection{Hourly Load study}

In order to further explain the heating mechanism of PCMs attached different surface of building envelopes, hourly load $\left(L_{H}\right)$, envelope surface temperatures ( $T_{\text {in }}$ and $\left.T_{\text {out }}\right)$, and hourly heat storage quality $\left(Q_{S}\right)$ for Model-S will be discussed as follow. Here, as shown in Figure 4, only some PCMs with a specific transition temperature range will contribute to the building energy use change by latent function, so PCMs with specific 
$T_{R}$ would be used to explain the trend in daily load curve.

3.1.2.1 PCMs attached to the external surface

Here, according to the results in above section (Figure 4a), PCMs with specific $T_{R}$ is used for explaining daily load curve trend, i.e. $T_{R}$ of $36^{\circ} \mathrm{C}$ for summer, and $T_{R}$ of $11^{\circ} \mathrm{C}$ and $18^{\circ} \mathrm{C}$ for winter curve, respectively.

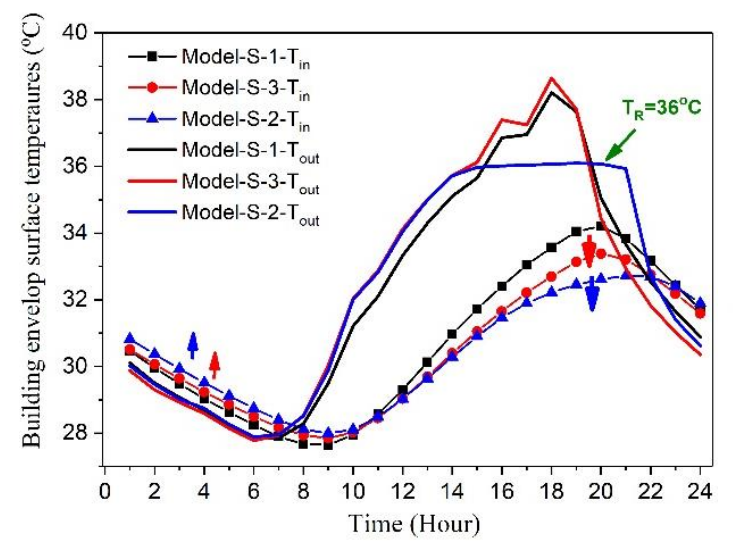

(a) Building envelop surface temperatures

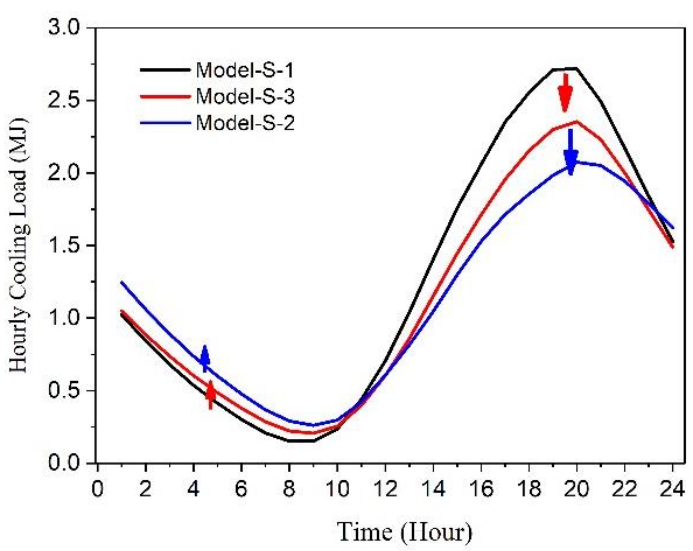

(b) Hourly cooling load

Figure 5: Hourly cooling load and building envelop surface temperatures on summer special day for Model-S with PCMs attached on external surface

First, PCMs with $T_{R}$ of $36^{\circ} \mathrm{C}$ is used for explaining the summer curve trend in Figure 4a. As shown in Figure 5a, for Model-S-3, the building envelope internal surface temperature $\left(T_{\text {in }}-\mathrm{S}-3\right)$ is reduced in the daytime between 12 and 22 o'clock, compared with $T_{i n}$-S-1; while in the early morning before 10 o'clock $T_{i n}-\mathrm{S}-3$ is increased a little. Then it can be found in Figure 5b, the hourly cooling load of Model-S-3 ( $\left.L_{H}-\mathrm{S}-3\right)$ is reduced and increased in the corresponding time period, respectively. This is caused by the envelope's thermal resistance increase by adding "Solid PCMs" (i.e. the function of the sensible heat of PCMs). Thus, as mentioned in Figure 4 a, daily cooling loads $\left(L_{D-}\right.$ cool) of Model-S-3 (Red dotted line) is reduced compared with the $L_{D}$ of Model-S-1 
(Black dotted line).

In addition, Figure 5a indicates that, for Model-S-2, envelop external surface temperature $\left(T_{\text {out }}-\mathrm{S}-2\right)$ is reduced in the daytime compared with $T_{\text {out }}-\mathrm{S}-3$, leading to further reduction of $T_{i n}-\mathrm{S}-2$. And it is interesting to note that there is a platform area on the $T_{\text {out }} \mathrm{S}-2$ curve of $36^{\circ} \mathrm{C}$, which is the same as the $T_{R}$ value of applied PCMs $\left(T_{R}\right.$ $=36^{\circ} \mathrm{C}$ ). This is attributed to that, in Model-S-2, PCMs undergoes a phase change at this time, and the $T_{\text {out }} \mathrm{S}-2$ is kept at $36^{\circ} \mathrm{C}$ in this period, thus reducing the heat transfer from the outdoor to the indoor. Hence, as showed in Figure 5a| and $\mathrm{b}$, the corresponding $T_{\text {in }}$ and $L_{H-c o o l}$ of Model-S-2 in this time period are further decreased compared with Model$\mathrm{S}-3$, that is to say, that PCMs further provides thermal insulation during the day. While, like the trends in Model-S-3, in the early morning $T_{\text {in }}$ and $L_{H-\text { cool }}$ in Model-S- 2 is only slightly reduced and increased in this corresponding time period, respectively. Therefore, as mentioned in Figure 4a, daily loads $\left(L_{D}\right)$ of Model-S-2 (Blue solid line) is further reduced compared with the $L_{D}$ of Model-S-3 (Red dotted line).

To further explain the latent heat function of PCMs, hourly heat storage quality $\left(Q_{S}\right)$ for this case is shown in Figure 6. It can be seen that in the daytime $Q_{S}$ for ModelS-3 and Model-S-2 is positive, which means that these two building envelopes with "Solid PCMs and PCMs absorb outdoor heat, then prevent heat into the building, thus reduce its hourly cooling load. Moreover, Figure 6 shows that from 12 o'clock, $Q_{S}$ for Model-S-2 begins to higher than that for Model-S-3, which is caused by the phase change of PCMs, i.e. heat absorb by melting. Due to the melting of PCMs, there is more heat storing in this envelope, then more positive $Q_{S}$ is got. Thus heat entering the 
building is further reduced, resulting in a lower $T_{i n-\mathrm{S}} \mathrm{S}-2$, which reduces the building's

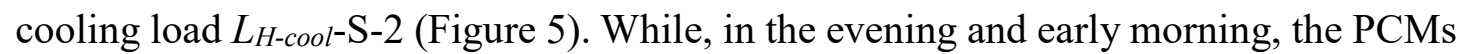
solidification let more heat releasing from this envelope, then more negative $Q_{S}$ is generated. Thus some heat is released into the outdoor air, and some enter the interior of the building, resulting in a little higher $T_{i n}$-S-2 and a slightly higher $L_{H-\text { cool }}$-S-2 (Figure 5). Therefore, the whole day cooling load $L_{D}$ of Model-S-2 by adding PCMs with $T_{R}$ of $36^{\circ} \mathrm{C}$ is reduced (Figure 4 ).

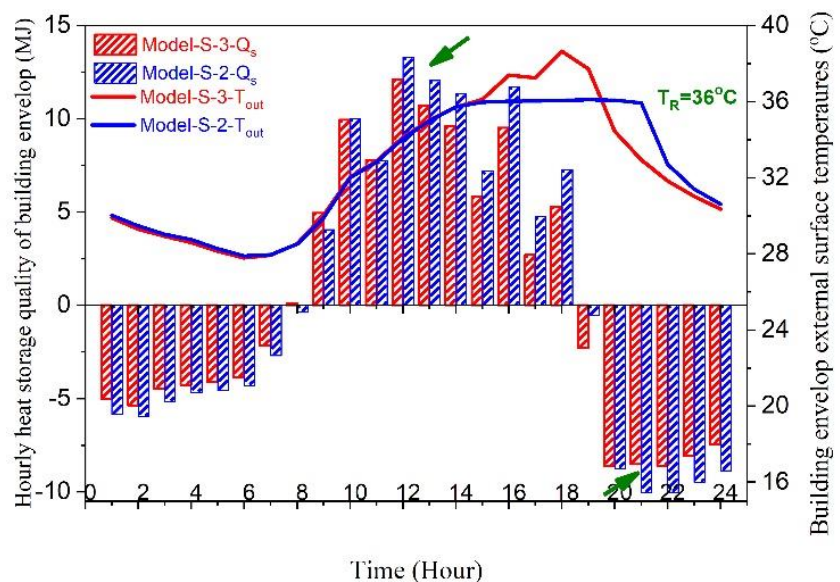

Figure 6: Hourly heat storage quality of on summer special day for Model-S with PCMs attached on external surface

Secondly, PCMs with $T_{R}$ of $11^{\circ} \mathrm{C}$ and $18^{\circ} \mathrm{C}$ are applied for explaining the winter curve trends in Figure 4a. As shown in Figure 7a, for Model-S-2, the phase change of PCMs with $T_{R}$ of $11^{\circ} \mathrm{C}$ and $18^{\circ} \mathrm{C}$ occur in early morning and daytime, respectively. These phase changes make their exterior surface temperatures $T_{\text {out }}$ keep consistent with their $T_{R}$ of $11^{\circ} \mathrm{C}$ and $18^{\circ} \mathrm{C}$, respectively. For the model with PCMs of low $T_{R}$ of $11^{\circ} \mathrm{C}$ (Blue curves), the lower $T_{\text {out }}$ in the early morning leads to lower interior surface temperature $T_{\text {in }}$ (Figure $7 \mathrm{~b}$ ), then resulting in higher hourly heating load $L_{H \text {-heat }}$ shown in Figure 7c. As a result, for Model-S-2 with low $T_{R}$ PCMs, a high daily heating load 
$L_{D \text {-heat }}$ will be needed, shown in winter curve in Figure 4a. For the model with PCMs of high $T_{R}$ of $18^{\circ} \mathrm{C}$ (Green curves), in the daytime, the lower $T_{\text {out }}$ also results in slightly higher hourly heating load $L_{H-h e a t}$. However, in the early morning, due to the heat release from PCMs, the higher $T_{\text {out }}$ is got in this period (Figure 7a), then there is a higher $T_{\text {in }}$ (Figure $7 \mathrm{~b}$ ), thus much lower $L_{H-h e a t}$ is needed (Figure $7 \mathrm{c}$ ). Hence, daily heating load $L_{D \text {-heat }}$ in Model-S-2 with high $T_{R}$ PCMs is increased as shown in winter curve in Figure 4a.

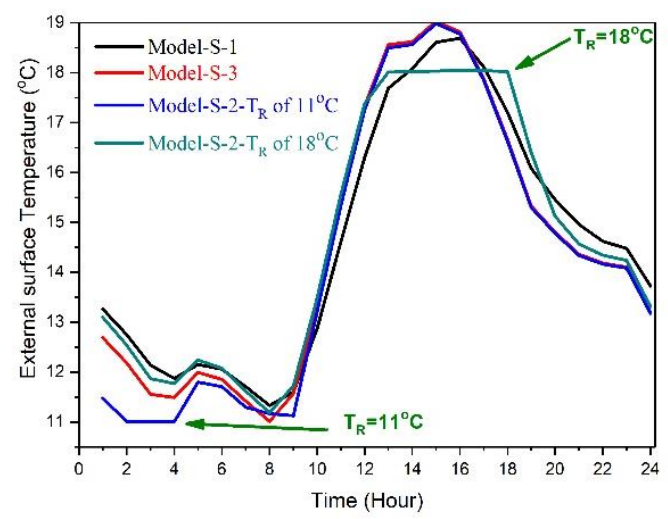

(a) External surface temperatures

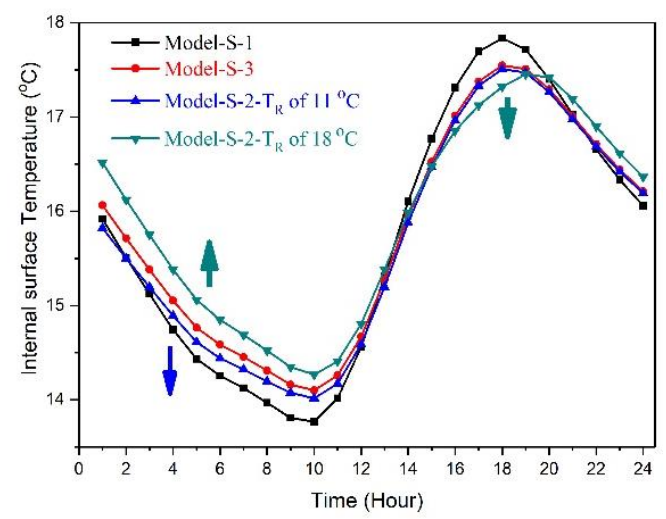

(b) Internal surface temperatures

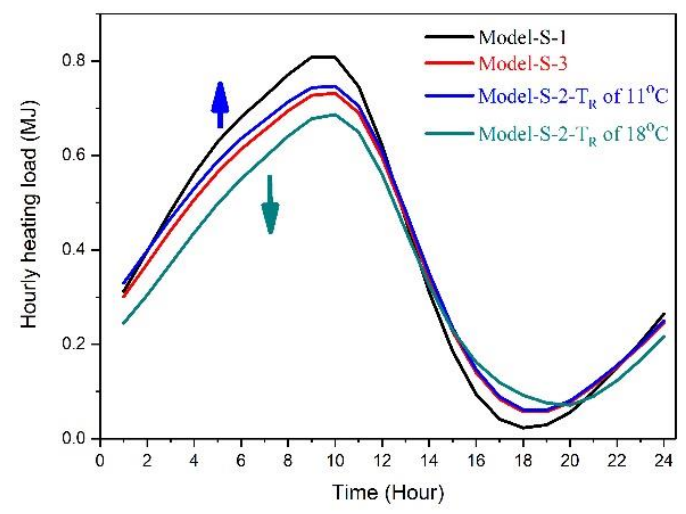

(c) Hourly heating load

Figure 7: Hourly heating load and building envelop surface temperatures on winter special day for Model-S with PCMs attached on external surface

In conclusion, the attaching of PCM layer to the external envelope surface will 
modulate the boundary conditions of the building envelope (envelope external surface temperature) to impact the heat exchanges between indoors and outdoors, resulting in the change of building energy performance. That is to say that when the PCM layer is attached to the external envelope surface, it plays as a thermal insulation material to protect buildings from the outside environment, which is due to its strong absorption and exothermic effect due to its latent heat function.

3.1.2.2 PCMs attached to the internal surface

Here, PCMs with specific $T_{R}$ of $30^{\circ} \mathrm{C}$, and $T_{R}$ of $17^{\circ} \mathrm{C}$ were applied for explaining daily load curve trend for summer and winter, respectively.
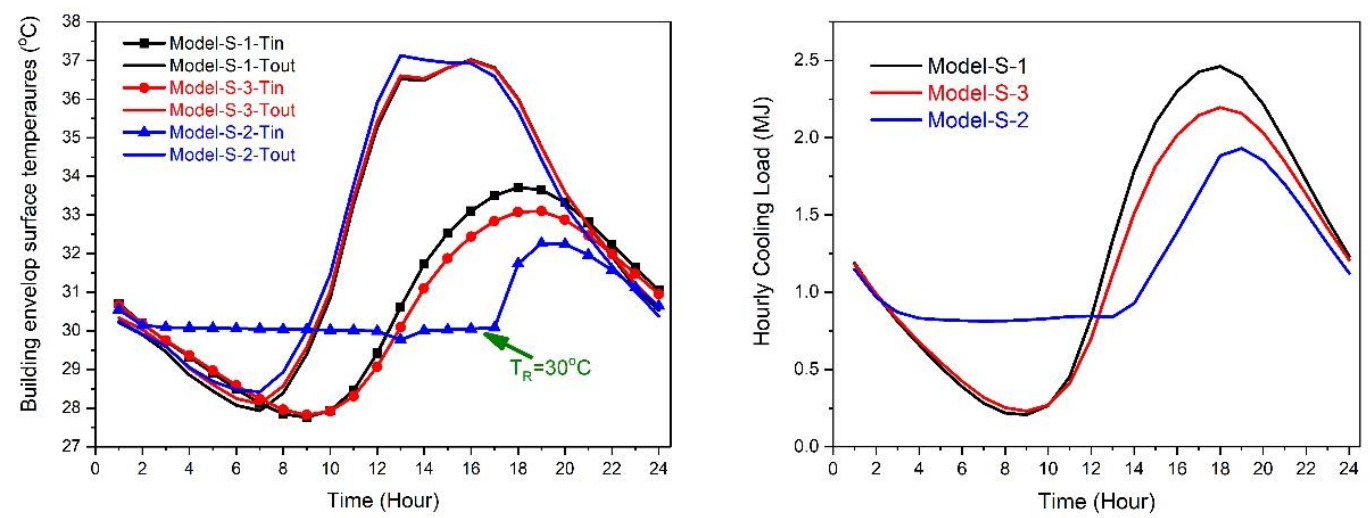

(a)Building surface temperatures on summer special day (b)Hourly cooling load on summer special day
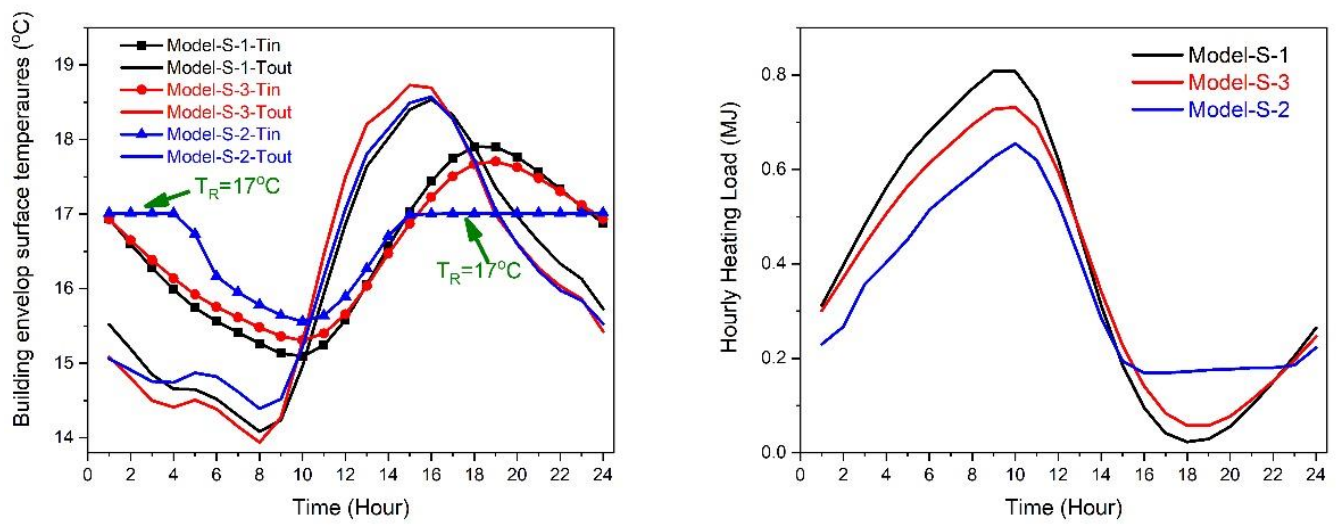

(c)Building surface temperatures on winter special day (d) Hourly heating load on winter special day

Figure 8: Hourly cooling and heating load and building envelope surface temperatures on special days for Model-S with PCMs attached on internal surface 
As shown in Figure 8a and c, for Model-S-2, the phase changes of PCMs with $T_{R}$ of $30^{\circ} \mathrm{C}$ and $17^{\circ} \mathrm{C}$ make their interior surface temperatures $T_{\text {in }}$ keep consistent with the $T_{R}$ of $30^{\circ} \mathrm{C}$ and $17^{\circ} \mathrm{C}$, respectively. For both models with PCMs of $T_{R}$ of $30^{\circ} \mathrm{C}$ and $17^{\circ} \mathrm{C}$, due to the changes of $T_{i n}$, the corresponding hourly loads $L_{H}$ are got. In summer, in the early morning, higher interior surface temperature $T_{\text {in }}$ (Figure $8 \mathrm{~b}$ ) results in higher hourly cooling load $L_{H-c o o l}$; while in the daytime low $T_{\text {in }}$ leads to low $L_{H \text {-cool }}$. As a result, for Model-S with PCMs on the internal envelope, attaching PCMs make a slightly negative role in summer, shown in summer curve in Figure 4b. In addition, in winter, the phenomenon is different. Specifically, in the early morning, heat release by PCMs leads to a higher $T_{\text {in }}$ (Figure 8c), resulting in lower $L_{H-c o o l}$; while in the daytime heat storage by PCMs reduces $T_{i n}$, leading to higher $L_{H-c o o l}$. As a result, for Model-S with PCMs on the internal envelope, attaching PCMs make a slightly positive role in winter (Figure 4b). Moreover, it can be concluded that, the PCMs' function doesn't be affected by the outdoor environment, which is only subjected to the indoor environment of buildings with PCMs attaching.

In conclusion, attaching PCMs into internal building envelope directly affect the interior temperatures of the building envelops, leading to the change of building energy performance. That is to say that, when the PCM layer is attached to the internal envelope surface, it plays as a system with the ability of energy storage and supply, to meet parts of energy demand of building indoor environment. 


\subsection{Applicability research of PCMs}

In this part, the PCMs applicability research was carried out by using Model-C, and for each climate, the optimal transition temperature range and energy saving rate would be given.

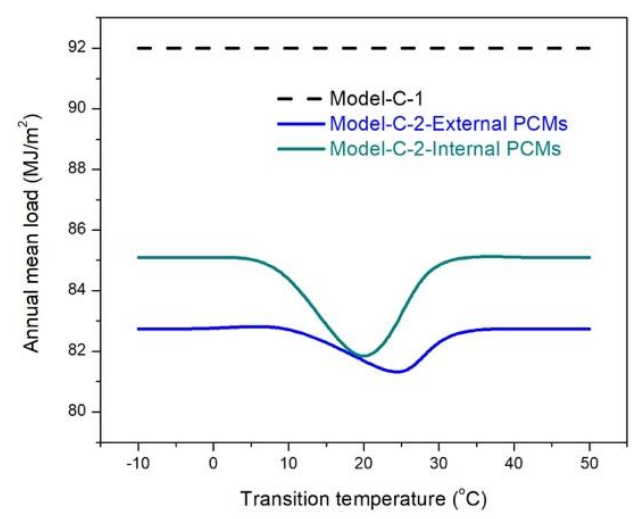

(a)Guangzhou

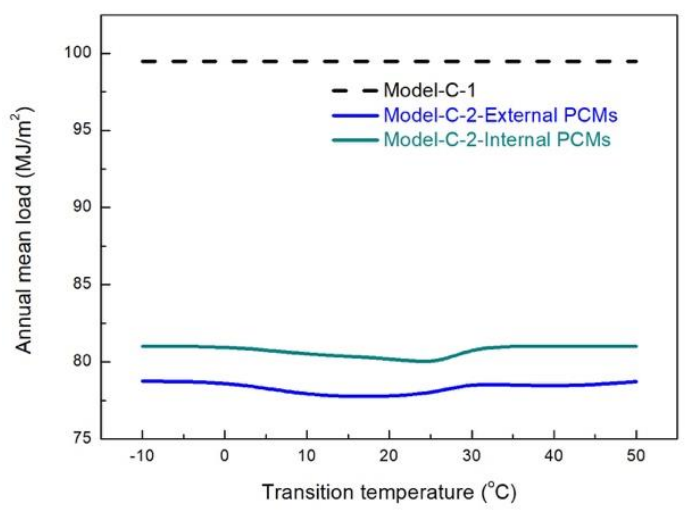

(c)Shanghai

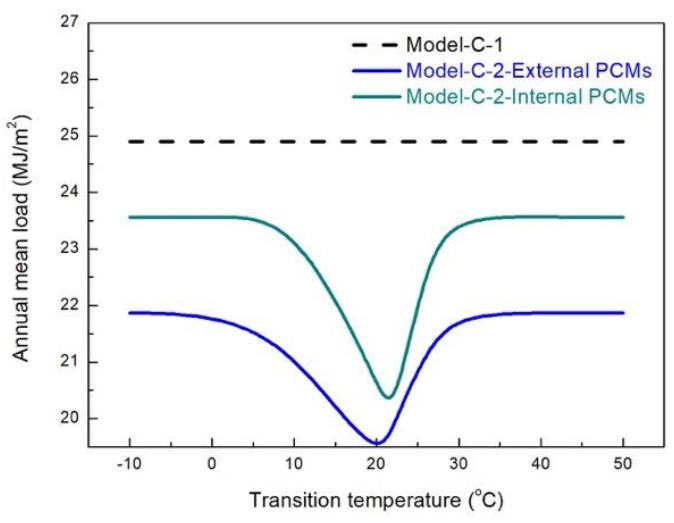

(b)Kunmin

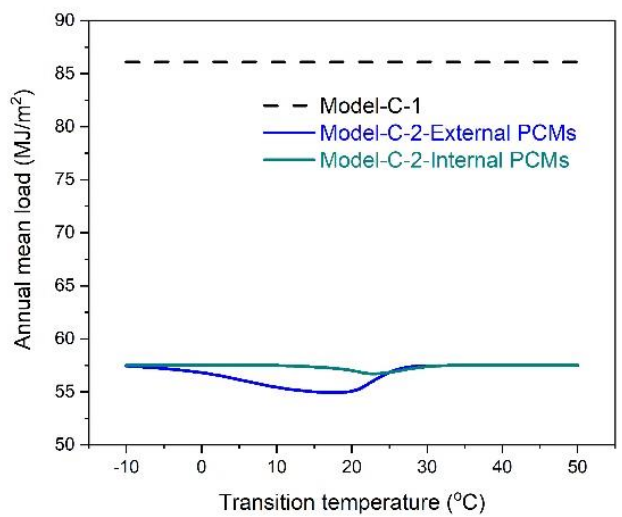

(d)Lhasa 


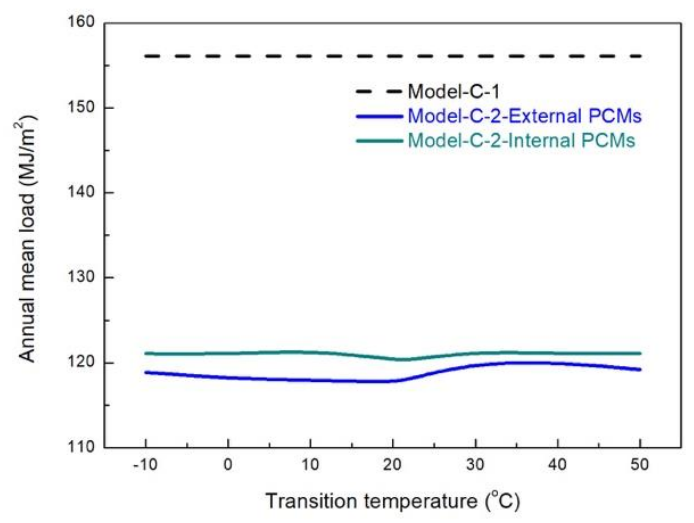

(e)Beijing

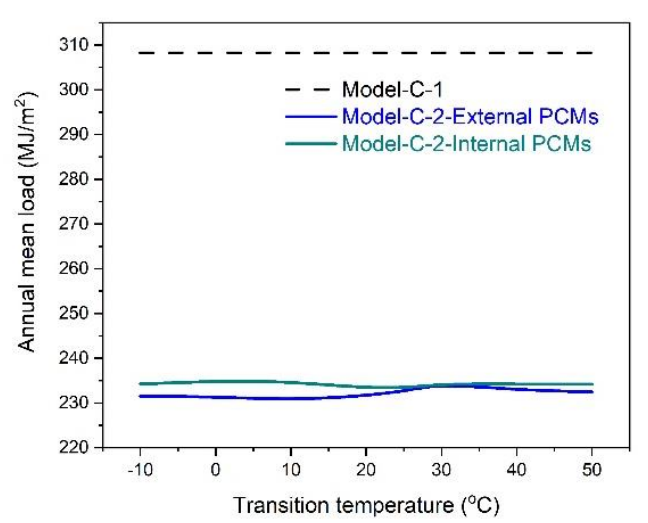

(f)Harbin

Figure 9: Annual mean load for Model-C with and without PCMs addition in different climates

Figure 9 indicates annual mean load for Model-C in different climates. First, for Guangzhou and Kunming, PCMs addition has a big effect on energy use as its latent heat function, which is due to their weather conditions are peaceful and not too fluctuating (as analyzed in Figure 2). Specifically, for buildings with external PCMs addition, PCMs with $T_{R}$ of near $26^{\circ} \mathrm{C}$ and $20^{\circ} \mathrm{C}$ can contribute to a positive influence on energy saving with corresponding energy saving rates of $12.0 \%$ and $22.8 \%$, for Guangzhou and Kunming respectively. It is interesting to found that, the ideal $T_{R}$ is basically consistent with their outdoor comprehensive temperature. Moreover, for both climates, in buildings with internal PCMs addition, PCMs with $T_{R}$ ranges of about $10 \sim 30^{\circ} \mathrm{C}$ can contribute to a positive influence on energy saving, and the both ideal $T_{R}$ for energy saving occur at about $22^{\circ} \mathrm{C}$ with corresponding energy saving rates of $12.4 \%$ and $20.1 \%$, which is subjected to its indoor set temperature.

In addition, for other climates, for both buildings no matter with internal or external PCMs addition, PCMs addition can decrease the energy use in buildings, while the contribution from PCMs' latent heat function to the energy savings is not significant. 
This is attributed to that the weather conditions in these climates are of big fluctuation, which is bad to play the latent heat function of the PCMs. Especially for Harbin, it should be noted that there is particularly high annual mean load, which is due to the extremely harsh outdoor low temperature environment in winter in Harbin. Therefore, for Harbin, it can be further found that, attaching PCMs on the building envelope is not applicable. However, for Lhasa, attaching PCMs with a transition temperature range of around $16^{\circ} \mathrm{C}$ on the external building envelope results in a certain positive effect on energy saving, which is because Lhasa has a small fluctuation in its outdoor comprehensive air temperature due to its high solar radiation in winter.

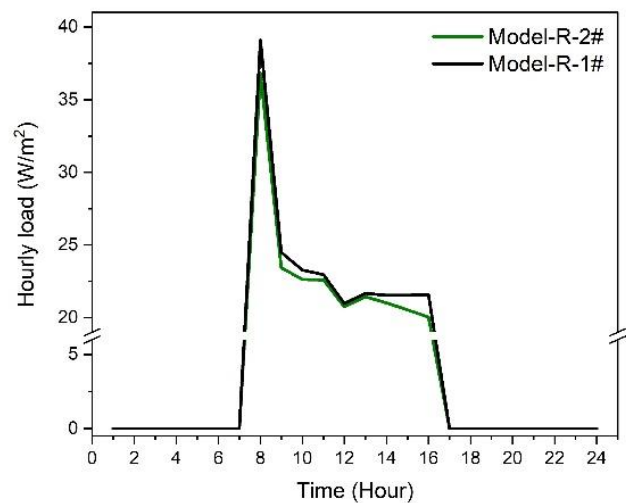

(a) Ilourly load in summer in Guangzhou

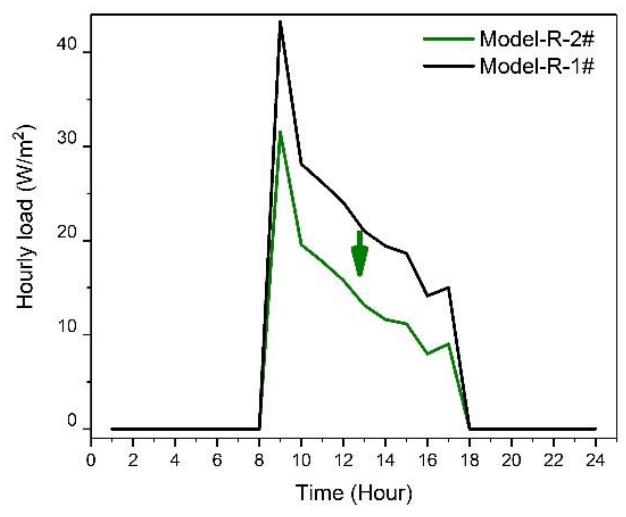

(c) Ilourly load in winter in Lhasa

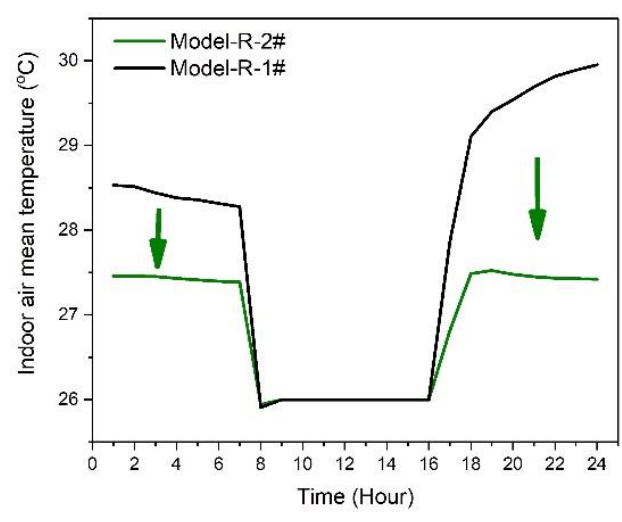

(b) Indoor air mean temperalure in summer in Guangょhou

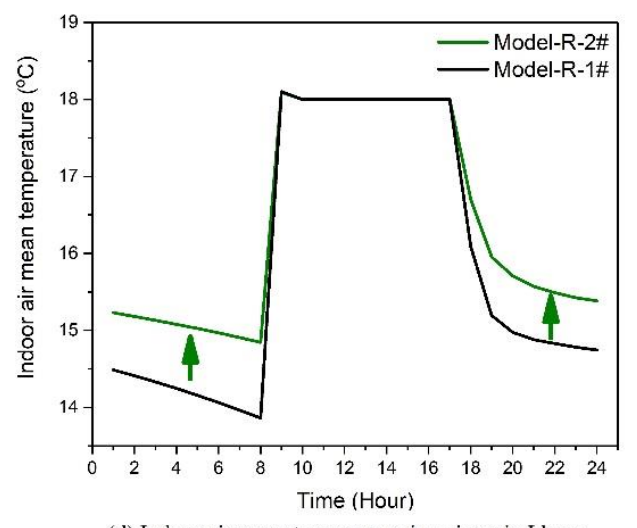

(d) Indoor air mean temperature in winter in Lhasa

Figure 10: Hourly load and indoor air mean temperature for Model-C with and without PCMs addition in Guangzhou and Lhasa 
Moreover, hourly load and indoor air mean temperature for Model-C in Guangzhou and Lhasa were shown in Figure 10. Firstly, Figure 10a and c indicate that with the addition of PCMs hourly loads of the more complicated building model decrease in both Guangzhou and Lhasa, leading to the reduction of total building energy supply. In addition, it is interesting to note that there are obvious hourly load peaks at 8 o'clock in both curves of Figure 10a and c, which is caused by the accumulated load during the whole night time, during which no energy supply system works. Specifically, during the night-times there is no energy supply system working, so at 8 o'clock when the energy supply system is just turned on, the system needs to process for the realization of the target indoor temperature of $26^{\circ} \mathrm{C}$ or $18^{\circ} \mathrm{C}$. And it can be seen that the addition of PCMs decreases the value of hourly peak load, which means that the installed capacity of an energy supply system such as air conditioning and heating equipment, can be reduced. Secondly, Figure $10 \mathrm{~b}$ and d indicate that, for the time period with no energy supply system working, compared to Model-C-1, indoor air mean temperature of Model-C-2 is closer to the set temperature of $26^{\circ} \mathrm{C}$ or $18^{\circ} \mathrm{C}$ in both Guangzhou and Lhasa. This phenomenon will lead to a more comfortable environment at this time period, and it is also the reason why hourly load at 8 o'clock is reduced for the models with PCMs application.

\section{Conclusion}

In this paper, two building models were carried out for analyzed applicability research of PCMs incorporated in building envelope by using EnergyPlus. The main findings are listed as follow: 
The PCM layer separately attached to the internal and external surface of building envelopes shows a different impact. First, the external PCM layer attaching plays as a thermal insulation material to protect buildings from the outside environment, which will be affected by the external environment. Secondly, when the PCM layer is attached to the internal envelope surface, it plays as an energy storage and supply system, to meet parts of building energy demand. And this function doesn't be affected by the outdoor environment, which is only subjected to its indoor environment of buildings with PCMs attaching.

In addition, the simulation results in Model-C gave the climate applicability investigation of PCMs. First, for climates with small fluctuation weather, such as Guangzhou and Kunming, for both internal and external PCMs addition separately, PCMs with appreciate transition temperature can contribute to positive influences on energy saving. In specific, for external PCMs addition, PCMs with $T_{R}$ of near $26^{\circ} \mathrm{C}$ and $20^{\circ} \mathrm{C}$ contribute to highest energy saving rates of $12.0 \%$ and $22.8 \%$, for Guangzhou and Kunming respectively. And for internal PCMs addition, PCMs with nearly same ideal $T_{R}$ of about $22^{\circ} \mathrm{C}$ lead to energy saving rates of $12.4 \%$ and $20.1 \%$. It is needed to note that the ideal $T_{R}$ is basically subjected to its outdoor comprehensive temperatures (25 ${ }^{\circ} \mathrm{C}$ for Guangzhou and $20{ }^{\circ} \mathrm{C}$ for Kunming) and its indoor set temperature for external and internal PCMs addition, respectively. Secondly, for other climates with big fluctuation weather conditions in the whole year, no matter internal or external PCMs addition, PCMs' latent heat function to the energy savings is not significant, and compared with the total large building energy use, it is inappropriate for the PCMs 
application.

\section{Acknowledgment}

This paper was supported by the National Natural Science Foundation of China (51708022). Supports by The Fundamental Research Funds for the Central Universities (FRF-TP-18-024A2) and Program of China Scholarships Council (201806465006) are also acknowledged.

\section{References}

[1]. Hossain, Faruque M. Solar energy integration into advanced building design for meeting energy demand and environment problem [J]. International Journal of Energy Research, 2016, 40(9):1293-1300.

[2]. Wei Y, Zhang X, Shi Y, et al. A review of data-driven approaches for prediction and classification of building energy consumption [J]. Renewable \& Sustainable Energy Reviews, 2018, 82:1027-1047.

[3]. Tian, Z, Zhang, X, Jin, X, Zhou, X, Si, B, \& Shi, X. Towards adoption of building energy simulation and optimization for passive building design: A survey and a review [J]. Energy and Buildings, 2018, 158, 1306-1316.

[4]. Kilkis B. Net-zero energy cities: A hub for decentralized energy for better environment [J]. International Journal of Energy Research, 2012, 36(15):1358-1365.

[5]. Le Guen, M, Mosca, L, Perera, A. T. D, Coccolo, S, Mohajeri, N, \& Scartezzini, J. L. Improving the energy sustainability of a Swiss village through building renovation and renewable energy integration [J]. Energy and Buildings, 2018, 158, 906-923. 
[6].Adamczyk J, Dylewski R. The impact of thermal insulation investments on sustainability in the construction sector[J]. Renewable \& Sustainable Energy Reviews, 2017, 80:421-429.

[7].Zhu M, Ji R, Li Z, et al. Preparation of glass ceramic foams for thermal insulation applications from coal fly ash and waste glass[J]. Construction and Building Materials, 2016, 112:398-405.

[8]. Ji R, Zhang Z, He Y, et al. Simulating the effects of anchors on the thermal performance of building insulation systems [J]. Energy and Buildings, 2017, 140:501507.

[9]. Rehman H.U. Experimental performance evaluation of solid concrete and dry insulation materials for passive buildings in hot and humid climatic conditions [J]. Applied Energy, 2017, 185:1585-1594.

[10]. Na Z, Shanshan L, Pingfang H, et al. A review on applications of shapestabilized phase change materials embedded in building enclosure in recent ten years [J]. Sustainable Cities and Society, 2018, 43:251-264.

[11]. Chen, C, Ling, H, Zhai, Z. J., Li, Y, Yang, F, Han, F., \& Wei, S. Thermal performance of an active-passive ventilation wall with phase change material in solar greenhouses [J]. Applied energy, 2018, 216:602-612.

[12]. Auzeby M, Shen W, Underwood C, et al. Using Phase Change Materials to Reduce Overheating Issues in UK Residential Buildings $\hat{\aleph}^{2}[\mathrm{~J}]$. Energy Procedia, 2017, 105:4072-4077.

[13]. Ling $\mathrm{H}$, Chen $\mathrm{C}$, Qin $\mathrm{H}$, et al. Indicators evaluating thermal inertia 
performance of envelops with phase change material[J]. Energy and Buildings, $2016,122: 175-184$.

[14]. Ling H, Chen C, Guan Y, et al. Active heat storage characteristics of activepassive triple wall with phase change material[J]. Solar Energy, 2014, 110:276-285.

[15]. Effect of phase change materials on indoor thermal environment under different weather conditions and over a long time [J]. Applied Energy, 2015, 140:329-337.

[16]. Konstantinidou C A, Lang W, Papadopoulos A M. Multiobjective optimization of a building envelope with the use of phase change materials (PCMs) in Mediterranean climates [J]. International Journal of Energy Research, 2018(4).

[17]. Wang Y, Zheng H , Feng H X , et al. Effect of preparation methods on the structure and thermal properties of stearic acid/activated montmorillonite phase change materials[J]. Energy and Buildings, 2012, 47:467-473.

[18]. Liu, F, Zhu, J, Liu, J, Ma, B, Zhou, W, \& Li, R. (2018). Preparation and properties of capric-stearic acid/White Carbon Black composite for thermal storage in building envelope. Energy and Buildings, 158, 1781-1789.

[19]. Ahmet Sarl, Bicer A, Karaipekli A, et al. Preparation, characterization and thermal regulation performance of cement based-composite phase change material[J]. Solar Energy Materials \& Solar Cells, 2018, 174:523-529.

[20]. Mankel, C., Caggiano, A., Ukrainczyk, N., \& Koenders, E. Thermal energy storage characterization of cement-based systems containing Microencapsulated-PCMs [J]. Construction and Building Materials, 2019, 199: 307-320. 
[21]. Liu, L., Peng, B., Yue, C., Guo, M., \& Zhang, M. Low-cost, shape-stabilized fly ash composite phase change material synthesized by using a facile process for building energy efficiency [J].Materials Chemistry and Physics, 2019, 222: 87-95.

[22]. Rashidi, S., Esfahani, J. A., \& Karimi, N. Porous materials in building energy technologies-A review of the applications, modelling and experiments [J]. Renewable and Sustainable Energy Reviews, 2018, 91: 229-247.

[23]. Boussaba, L., Foufa, A., Makhlouf, S., Lefebvre, G., \& Royon, L. Elaboration and properties of a composite bio-based PCM for an application in building envelopes [J]. Construction and Building Materials, 2018, 185:156-165.

[24]. Ryms, M., \& Klugmann-C adziemska, E. Possibilities and benefits of a new method of modifying conventional building materials with phase-change materials (PCMs) [J]. Construction and Building Materials, 2019, 211:1013-1024.

[25]. Saxena, R., Rakshit, D., \& Kaushik, S. C. Phase change material (PCM) incorporated bricks for energy conservation in composite climate: A sustainable building solution [J]. Solar Energy, 2019, 183:276-284.

[26]. Marani, A., \& Madhkhan, M. An innovative apparatus for simulating daily temperature for investigating thermal performance of wallboards incorporating PCMs [J]. Energy and Buildings, 2018,167:1-7.

[27]. Konstantinidou, C. A., Lang, W., \& Papadopoulos, A. M. Multiobjective optimization of a building envelope with the use of phase change materials (PCMs) in Mediterranean climates [J]. International Journal of Energy Research, 2018, 42(9), 3030-3047. 
[28]. Berardi, U., \& Soudian, S. Experimental investigation of latent heat thermal energy storage using PCMs with different melting temperatures for building retrofit [J]. Energy and Buildings, 2019,185:180-195.

[29]. Wilson, J. A., Haghshenas, M., \& Kumar, R. Phase-change mechanism for evaporation in porous media using volume of fluid: Implicit formulation of interfacial temperature [J]. International Communications in Heat and Mass Transfer, 2019,103: 90-99.

[30]. Cheng, W. L., Li, W. W., Nian, Y. L., \& Xia, W. D. Study of thermal conductive enhancement mechanism and selection criteria of carbon-additive for composite phase change materials [J]. International Journal of Heat and Mass Transfer, 2018, 116:507511.

[31]. Zhou, Y., Chuck, W. F., \& Zhang, G. Study on heat-transfer mechanism of wallboards containing active phase change material and parameter optimization with ventilation [J]. Applied Thermal Engineering, 2018, 144: 1091-1108.

[32]. Soudian S, Berardi U. Assessing the effect of night ventilation on PCM performance in high-rise residential buildings [J]. Journal of Building Physics, 2019: 1744259119848128.

[33]. Berardi U, Soudian S. Benefits of latent thermal energy storage in the retrofit of Canadian high-rise residential buildings [J]. Building Simulation, 2018, 11(1).

[34]. Sang Y, Zhao J R, Sun J, et al. Experimental investigation and EnergyPlusbased model prediction of thermal behavior of building containing phase change material [J]. Journal of Building Engineering, 2017, 12:259-266. 
[35]. Tabares-Velasco P C, Christensen C, Bianchi M. Verification and validation of EnergyPlus phase change material model for opaque wall assemblies [J]. Building \& Environment, 2012, 54(7):186-196.

[36]. Chen X M, Ren J, Xie Z W, et al. Temperature and Energy Consumption Simulation of Phase Change Materials Applied to Building Exterior Wall [J]. Building Energy Efficiency, 2017.

[37]. Zhang Y, Cui H, Tang W, et al. Effect of Summer Ventilation on the Thermal Performance and Energy Efficiency of Buildings Utilizing Phase Change Materials [J]. Energies, 2017, 10(8):1214.

\section{Table and Figure captions:}

Table 1: Basic thermo-physical properties of construction materials

Figure1: Simulation models used in this study

Figure 2: Annual outdoor meteorological parameters of three weather zones

Figure 3: Schedules of interior heat source and energy supply system

Figure 4: Daily loads and outdoor specially day weather condition for a simplified cabin model located in Guangzhou

Figure 5: Hourly cooling load and building envelop surface temperatures on summer special day for Model-S with PCMs attached on external surface

Figure 6: Hourly heat storage quality of on summer special day for Model-S with PCMs attached on external surface

Figure 7: Hourly heating load and building envelop surface temperatures on winter special day for Model-S with PCMs attached on external surface 
Figure 8: Hourly cooling and heating load and building envelope surface temperatures on special days for Model-S with PCMs attached on internal surface

Figure 9: Annual mean load for Model-C with and without PCMs addition in different climates

Figure 10: Hourly load and indoor air mean temperature for Model-C with and without PCMs addition in Guangzhou and Lhasa 